\title{
MEDIA LEAFLET MENCEGAH LEPRA DI DESA KAYULOMA KECAMATAN BASIDONDO KABUPATEN TOLI-TOLI
}

\section{Leaflet Media to Prevention of Leprosy In The Kayulompa Village Basidondo District of Tolitoli Regency}

\author{
Yulianus Sudarman H Melangka \\ Poltekkes Kemenkes Palu \\ (darmafitara@yahoo.co.id, 082194146065)
}

\begin{abstract}
ABSTRAK
Penelitian ini bertujuan untuk mengetahui pengaruh edukasi metode ceramah dengan media leaflet terhadap peningkatan pengetahuan, sikap dan tindakan penderita kusta dalam rangka pencegahan penyakit kusta di Desa Kayulompah Kecamatan Basidondo Kabupaten Tolitoli. Metode penelitian yang digunakan yaitu quasi eksperiment non-randomized pre dan posttest only control design. Sampel yang digunakan adalah 40 penderita kusta dengan teknik pengambilan sampel yaitu purposive sampling. Variabel bebasnya yaitu edukasi metode ceramah dengan media leaflet tentang penyakit kusta dan pencegahannya, sedangkan variabel terikatnya yaitu pengetahuan, sikap dan tindakan responden. Teknik analisis data dilakukan dengan paired sample t-test. Hasil penelitian menunjukkan bahwa terdapat pengaruh intervensi edukasi menggunakan metode ceramah dengan media leaflet terhadap peningkatan pengetahuan, sikap dan tindakan penderita kusta dalam pencegahan penyakit kusta. Hal ini dibuktikan dari nilai signifikansi (p) pretest dan postest pada masing-masing variabel lebih kecil taraf signifikansi $5 \%$ yaitu pengetahuan sebesar 0,000 ; sikap sebesar 0,000 dan tindakan sebasar 0,000. Nilai rerata pengetahuan, sikap dan tindakan responden yang mengalami peningkatan setiap minggunya menunjukkan bahwa terdapat pengaruh intervensi edukasi menggunakan metode ceramah dengan media leaflet terhadap peningkatan pengetahuan, sikap dan tindakan penderita kusta dalam pencegahan penyakit kusta. Disarankan agar edukasi menggunakan metode ceramah dengan media leaflet dijadikan prosedur dalam pencegahan penyakit kusta.
\end{abstract}

Kata kunci : Penyakit Kusta, Edukasi Kesehatan, Media Leaflet

\section{ABSTRACT}

Leprosy is one of the infectious diseases caused by Mycobakterium leprae. Lack of knowledge, attitudes and actions against leprosy, making this disease feared by the public. This study aims to knowing the effect of education method with leaflet media on knowledge, attitude and actions on behavior of leprosy patients to prevention of leprosy in the Kayulompah Village Basidondo District of Tolitoli Regency. This study used quasi eksperimen technique with non-randomized pre dan posttest only control design. The study sample are the 40 leprosy patients with purposive sampling technique. The independent variables are educational methods of lectures with media leaflets about leprosy and it's prevention, while the dependent variable is knowledge, attitude and action of respondent. The technique of data analysis used paired sample t-test. The result of the study show that there are influence of educational intervention using lecture method with media leaflet on knowledge, attitude and actions on behavior of leprosy patients to prevention of leprosy in the Kayulompah Village Basidondo District of Tolitoli Regency 2017. It is proved by the p-value of pretest and posttest in each variable is significantly smaller than $0.05(5 \%)$ is knowledge 0,000; attitude is 0,000 and actions is 0,000 . The average value of knowledge, attitudes and actions of respondents who experienced an increase each week, show that intervention using lecture method with media leaflet give a positive impact of change on knowledge, attitudes and actions of leprosy patients and prevention.

Keywords : leprosy, health education, leaflet media 


\section{PENDAHULUAN}

Penyakit kusta merupakan salah satu penyakit menular yang menimbulkan masalah yang sangat kompleks. Masalah yang dimaksud bukan hanya dari segi medis tetapi meluas sampai masalah sosial, ekonomi, budaya keamanan dan ketahanan nasional, penyakit kusta pada umumnya terdapat di negara-negara yang sedang berkembang sebagai akibat keterbatasan kemampuan negara tersebut dalam memberikan pelayanan yang memadai dalam bidang kesehatan, pendidikan, dan kesejahteraan sosial ekonomi pada masyarakat ${ }^{(1)}$.

Pada tahun 2013 dilaporkan prevalensi kusta 7,9 per100.000 penduduk dengan penemuan kasus baru (NCDR) 6,75/100.000 penduduk, diantaranya merupakan tipe Multi Basiler (MB) 83,42\%, anak (0-14 Tahun) 11,88\%, dan Cacat Tingkat II 6.82\%. Pada tahun 2014 dilaporkan prevalensi kusta 7,9 per $/ 100.000$ penduduk dengan penemuan kasus baru (NCDR) 6,75/100.000 penduduk, diantaranya merupakan tipe Multi Basiler (MB) 83,5\%, anak (0-14 Tahun) 11,12\%, Cacat Tingkat II $9 \%$.

Penelitian senada oleh Ishak, dkk (2013) tentang implementasi penyuluhan kesehatan terhadap perubahan dan sikap tentang penyakit kusta pada masyarakat desa suka pindah kecamatan rambutan kabupaten banyuasi, jenis penelitian adalah quasi eksperimental dengan pre dan post test group, analisis yang digunakan adalah uji t-test untuk mengetahui pengaruh pendidikan kesehatan terhadap pengetahuan dan sikap sebelum dan sesudah diberikan pendidikan kesehatan, dengan hasil didapatkan nilai p 0,000 menunjukan ada pengaruh pemberian pendidikan kesehatan terhadap pengetahuan dan sikap tentang penyakit kusta ${ }^{(2)}$.

Senada dengan penelitian Mega Arianti Puri, Harmayetty, Budi Utomu, tentang Psycoeducative Family Therapy Mempengaruhi Pengetahuan, Dukungan Keluarga dan Stigma Kusta, jenis penelitian yang digunakan adalah Quasi experiment, dengan sampel kelompok intervensi dan kelompok pembanding, hasil statistik menunjukan bahwa hubungan yang signifikan antara Psychoeducative keluarga dengan pengetahuan $(\mathrm{p}=0,000)^{(3)}$.

Berdasarkan data dari Dinas Kesehatan Provinsi Sulawesi Tengah tahun 2016, bahwa dari 13 kabupaten/kota yang ada di sulawesi tengah terlihat tren kasus baru dari tahun 2013 s/d 2015 total kasus baru berturut-turut Tahun 2013 prevalensi 1,10/10.000 penduduk, tahun 2014 prevalensi 0.88/10.000 penduduk dan di akhir tahun 2015 prevalensi kusta mengalami kenaikan 1,59/10.000 penduduk. Dimana trend kasus baru pada tahun 2015 tertinggi ada di kabupaten Tojo Una-Una sebesar 4,81/10.000 Penduduk diikuti kabupaten Tolitoli sebesar 4,18/10.000 Penduduk, Kabupaten Morowali sebesar 2,93/10.000 penduduk, kabupaten Sigi sebesar 2,45/10.000 penduduk, kabupaten Buol sebesar 1,68/10.000 penduduk, kabupaten Donggala sebesar 1,50/10.000 penduduk dan kabupaten parigi moutong sebesar 1,20/10.000 Penduduk ${ }^{(4)}$.

Berdasarkan data yang diperoleh dari Dinas Kesehatan Kabupaten Tolitoli pada 
tahun 2016, jumlah unit pelayanan kesehatan sebanyak 14 puskesmas dan 1 Rumah Sakit dengan jumlah pengelola program kusta sebanyak 23 orang dengan status pelatihan $30 \%$ belum terlatih, mengikuti pelatihan lebih dari lima tahun yang lalu sebanyak $13 \%$ dan pelatihan lebih dari tiga tahun yang lalu sebanyak $17 \%$. Jumlah kasus baru kusta tahun 2014 sebanyak 32 kasus prevalensi 1,47/10.000 penduduk dan tahun 2015 sebanyak 91 kasus prevalensi 4,18/10.000 penduduk dengan jumlah kasus Paucibacillary (PB) 26 orang (28.6\%), Multibacillary (MB) 65 orang (71.4\%), anak 15 orang (16,3\%), cacat tingkat II sebanyak 2 orang (2.19\%) dan yang mengalami reaksi kusta sebanyak 7 orang. Angka tersebut menandakan bahwa masih banyaknya sumber penularan dan resiko terjadinya reaksi kusta dan kecacatan ${ }^{(5)}$.

Hasil wawancara dan observasi awal yang dilakukan oleh peneliti tanggal 03 Oktober 2016 pada penderita kusta di Kabupaten Tolitoli mengatakan, bahwa pemahaman, sikap dan tindakan mereka dalam pencegahan dan untuk memperoleh perawatan masih sangat kurang baik khususnya dalam melakukan pemeriksaan rutin pada penderita kusta. Sehingga resiko terjadinya reaksi kusta dan kecacatan dapat meningkat. Itulah sebabnya pemberian pendidikan kesehatan sangat penting dilakukan dalam hal Pemeriksaan fungsi saraf secara rutin sangat penting untuk dilakukan dalam upaya pencegahan cacat secara dini.

Pendidikan kesehatan adalah suatu upaya atau kegiatan untuk menciptakan perilaku masyarakat yang kondusif untuk kesehatan. Pendidikan kesehatan bukan hanya tingkat kesadaran atau pengetahuan masyarakat tentang kesehatan, namun yang lebih penting adalah mencapai perilaku.

Penelitian bertujuan untuk mengetahui pengaruh edukasi metode ceramah dengan media leaflet terhadap perilaku penderita kusta yang meliputi pengetahuan, sikap dan tindakan dalam rangka pencegahan penyakit kusta di Desa Kayulompa, Kecamatan Basidondo, Kabupaten Tolitoli.

\section{METODE PENELITIAN}

Jenis penelitian ini adalah penelitian kualitatif. Rancangan penelitian yang digunakan adalah quasi eksperiment nonrandomized pre dan posttest only control design. Dalam Penelitian ini sebelum memberikan perlakuan dilakukan pengambilan data awal kemudian diberikan perlakuan yaitu edukasi menggunakan metode ceramah dengan leaflet, selanjutnya dilakukan pengambilan data akhir. Kategori yang digunakan dalam penelitian ini yaitu distribusi kategori tiga dengan kriteria "Baik", "Cukup" dan “Kurang”. Pengetahuan yang dimaksud dalam penelitian ini yaitu tentang apa yang dipahami penderita kusta tentang penyakit kusta dan pencegahannya. Sikap yang dimaksudkan dalam penelitian ini adalah respon penderita kusta tentang penyakit kusta, penyebab kusta, pencegahan komplikasi pengenalan dini gejala kusta. Tindakan yang dimaksudkan dalam penelitian ini adalah tindakan penderita kusta dalam rangka pencegahan penyakit kusta. 


\section{HASIL}

Tabel 1 menunjukkan bahwa sebelum (pretest) diberikan edukasi dengan metode ceramah melalui media leaflet, pengetahuan responden tentang penyakit kusta dan pencegahan penyakit kusta sebagian besar masih termasuk cukup $(75,5 \%)$ dan masih terdapat $17,7 \%$ responden termasuk dalam kategori kurang. Namun setelah diberikan edukasi tentang penyakit kusta dan pencegahan penyakit kusta.

Tabel 1. Distribusi Kategori Variabel Pengetahuan Penderita Kusta

\begin{tabular}{cccccc}
\hline \multirow{2}{*}{ Interval } & Pretest & M1 & M2 & Postest & \multirow{2}{*}{ Kategori } \\
\cline { 2 - 4 } & F (\%) & F (\%) & F (\%) & F (\%) & \\
\hline $\mathrm{X}<5$ & $7(17,5 \%)$ & $0(0,0 \%)$ & $0(0,0 \%)$ & $0(0,0 \%)$ & Kurang \\
$5 \leq \mathrm{X}<10$ & $31(75,5 \%)$ & $15(37,5 \%)$ & $4(10,0 \%)$ & $0(0,0 \%)$ & Cukup \\
$\mathrm{X} \geq 10$ & $2(5,0 \%)$ & $25(62,5 \%)$ & $36(90,0 \%)$ & $40(100,0 \%)$ & Baik \\
$\Sigma$ & $40(100 \%)$ & $40(100 \%)$ & $40(100 \%)$ & $40(100 \%)$ & \\
\hline
\end{tabular}

Data Primer, 2017

Tabel 2. Distribusi Kategori Variabel Sikap Penderita Kusta

\begin{tabular}{cccccc}
\hline \multirow{2}{*}{ Interval } & Pretest & M1 & M2 & Postest & \multirow{2}{*}{ Kategori } \\
\cline { 2 - 4 } & F (\%) & F (\%) & F (\%) & F (\%) & \\
\hline $\mathrm{X}<24$ & $8(20,0 \%)$ & $0(0,0 \%)$ & $0(0,0 \%)$ & $0(0,0 \%)$ & Kurang \\
$24 \leq \mathrm{X}<36$ & $32(80,0 \%)$ & $22(55,0 \%)$ & $8(20,0 \%)$ & $3(7,5 \%)$ & Cukup \\
$\mathrm{X} \geq 36$ & $0(0,0 \%)$ & $18(45,0 \%)$ & $32(80,0 \%)$ & $37(92,5 \%)$ & Baik \\
$\Sigma$ & $40(100 \%)$ & $40(100 \%)$ & $40(100 \%)$ & $40(100 \%)$ & \\
\hline
\end{tabular}

Data Primer, 2017

Tabel 3. Distribusi Kategori Variabel Tindakan Penderita Kusta

\begin{tabular}{cccccc}
\hline \multirow{2}{*}{ Interval } & Pretest & M1 & M2 & Postest & \multirow{2}{*}{ Kategori } \\
\cline { 2 - 4 } & F (\%) & F (\%) & F (\%) & F (\%) & \\
\hline$X<24$ & $5(12,5 \%)$ & $0(0,0 \%)$ & $0(0,0 \%)$ & $0(0,0 \%)$ & Kurang \\
$24 \leq \mathrm{X}<36$ & $27(67,5 \%)$ & $13(32,5 \%)$ & $9(22,5 \%)$ & $0(0,0 \%)$ & Cukup \\
$\mathrm{X} \geq 36$ & $8(20,0 \%)$ & $27(67,5 \%)$ & $31(77,5 \%)$ & $40(100,0 \%)$ & Baik \\
$\Sigma$ & $40(100 \%)$ & $40(100 \%)$ & $40(100 \%)$ & $40(100 \%)$ & \\
\hline
\end{tabular}

Data Primer, 2017

menggunakan metode ceramah dengan leaflet, pengetahuan responden mengalami peningkatan setiap minggunya. Pada akhir minggu (posttest) $100 \%$ pengetahuan responden dalam kategori baik. Hal ini berarti bahwa edukasi dengan metode ceramah melalui media leaflet memberikan perubahan yang positif terhadap responden.

Tabel 2 menunjukkan bahwa sebelum (pretest) diberikan edukasi dengan metode ceramah melalui media leaflet, sikap atau responden tentang penyakit kusta dan pencegahan penyakit kusta $80 \%$ dalam kategori cukup dan masih terdapat 20,0\% responden termasuk dalam kategori kurang. Namun setelah diberikan edukasi tentang penyakit kusta dan pencegahan penyakit kusta menggunakan metode ceramah dengan leaflet, sikap responden mengalami peningkatan setiap minggunya. Pada akhir minggu (posttest) 
92,5\% sikap responden dalam kategori baik. Hal ini berarti bahwa edukasi dengan metode ceramah melalui media leaflet memberikan perubahan sikap yang positif terhadap responden.

Tabel 3 menunjukkan bahwa sebelum (pretest) diberikan edukasi dengan metode ceramah melalui media leaflet, tindakan responden tentang pencegahan penyakit kusta $67,5 \%$ dalam kategori cukup dan masih terdapat $12,5 \%$ responden termasuk dalam kategori kurang. Namun setelah diberikan edukasi tentang penyakit kusta dan pencegahan penyakit kusta menggunakan metode ceramah dengan leaflet, sikap responden mengalami peningkatan setiap minggunya. Pada akhir minggu (posttest) 100\% tindakan responden dalam kategori baik. Hal ini berarti bahwa edukasi dengan metode ceramah melalui media leaflet memberikan perubahan yang positif terhadap tindakan responden dalam rangka pencegahan penyakit kusta.

Perbandingan distribusi kategori tingkat pengetahuan responden tentang penyakit kusta dan pencegahan penyakit kusta pada setiap minggunya dapat dilihat pada Gambar 1:

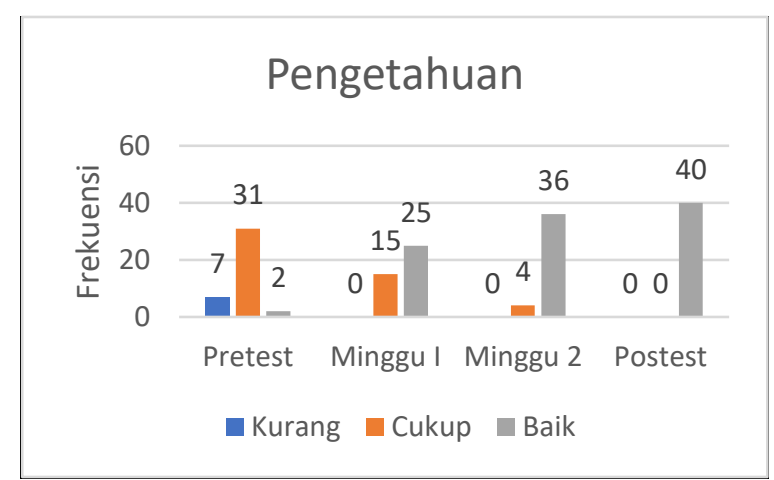

Gambar 1. Perbandingan Distribusi Kategorisasi Variabel Pengetahuan

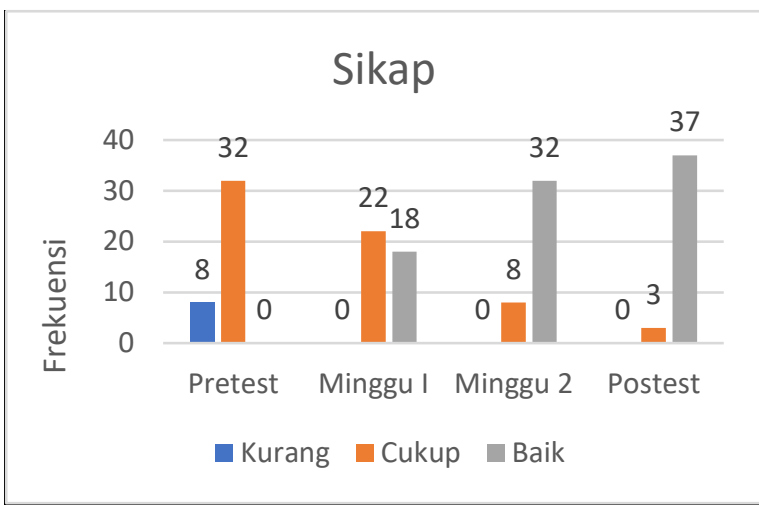

Gambar 2. Perbandingan Distribusi Kategorisasi Variabel Sikap

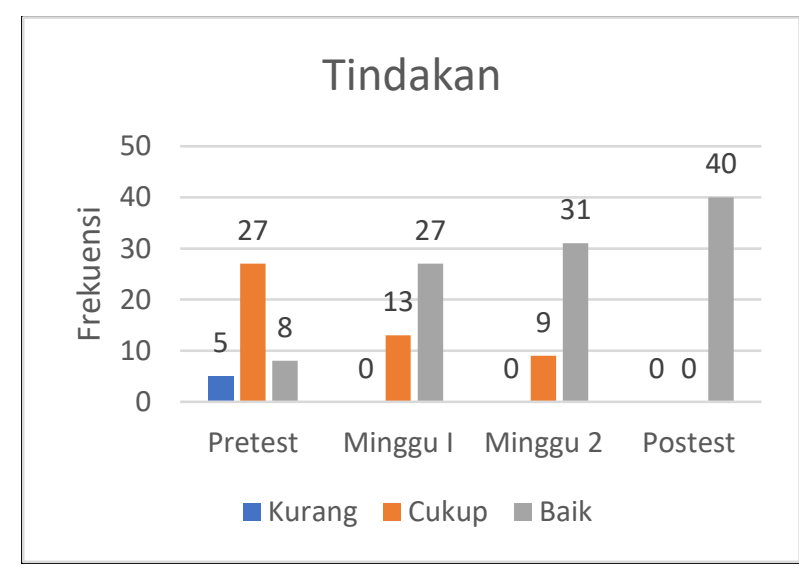

Gambar 3. Perbandingan Distribusi Kategorisasi Variabel Tindakan

Tabel 4. Perbandingan Hasil Analisis Uji-t Variabel Pengetahuan

\begin{tabular}{lllccccc}
\hline \multicolumn{1}{c}{ Variabel } & Kelompok & N & Mean & $\begin{array}{c}\text { Std. } \\
\text { Deviation }\end{array}$ & $\begin{array}{c}\text { Mean } \\
\text { Difference }\end{array}$ & t-hitung & p-value \\
\hline Pretest - M1 & Pretest & 40 & 7,475 & 2,075 & 2.825 & 7,974 & 0,000 \\
& Minggu 1 & 40 & 10,300 & 1,556 & & & \\
M1 - M2 & Minggu 1 & 40 & 10,300 & 1,556 & 2,425 & 2,425 & 0,000 \\
& Minggu 2 & 40 & 12,725 & 1,768 & & & \\
M2 - Postest & Minggu 2 & 40 & 12,725 & 1,768 & 0,700 & 2,183 & 0,035 \\
\hline
\end{tabular}

Data Primer, 2017 
Tabel 5 Perbandingan Hasil Analisis Uji-t Variabel Sikap

\begin{tabular}{|c|c|c|c|c|c|c|c|}
\hline Variabel & Kelompok & $\mathrm{N}$ & Mean & $\begin{array}{c}\text { Std. } \\
\text { Deviation }\end{array}$ & $\begin{array}{c}\text { Mean } \\
\text { Difference }\end{array}$ & t-hitung & p-value \\
\hline \multirow{2}{*}{ Pretest - M1 } & Pretest & 40 & 29,650 & 4,288 & \multirow{2}{*}{5,425} & \multirow{2}{*}{5,114} & \multirow{2}{*}{0,000} \\
\hline & Minggu 1 & 40 & 35,075 & 4,002 & & & \\
\hline \multirow{2}{*}{$\mathrm{M} 1-\mathrm{M} 2$} & Minggu 1 & 40 & 35,075 & 4,002 & \multirow{2}{*}{3,200} & \multirow{2}{*}{4,171} & \multirow{2}{*}{0,000} \\
\hline & Minggu 2 & 40 & 38,275 & 3,573 & & & \\
\hline \multirow{2}{*}{ M2 - Postest } & Minggu 2 & 40 & 38,275 & 3,573 & \multirow{2}{*}{1,475} & \multirow{2}{*}{2,055} & \multirow{2}{*}{0,047} \\
\hline & Postest & 40 & 39,750 & 3,550 & & & \\
\hline
\end{tabular}

Data Primer, 2017

Tabel 6 Perbandingan Hasil Analisis Uji-t Variabel Tindakan

\begin{tabular}{llllcccc}
\hline Variabel & Kelompok & N & Mean & $\begin{array}{c}\text { Std. } \\
\text { Deviation }\end{array}$ & $\begin{array}{c}\text { Mean } \\
\text { Difference }\end{array}$ & t-hitung & p-value \\
\hline \multirow{2}{*}{ Pretest - M1 } & Pretest & 40 & 26,675 & 3,058 & 4,450 & 7,249 & 0,000 \\
& Minggu 1 & 40 & 31,125 & 3,073 & & & 0,000 \\
M1 - M2 & Minggu 1 & 40 & 31,125 & 3,073 & 1,350 & 4,125 & 0,000 \\
& Minggu 2 & 40 & 32,475 & 2,864 & & & \\
M2 - Postest & Minggu 2 & 40 & 32,475 & 2,864 & 2,475 & 6,811 & \\
\hline
\end{tabular}

Data Primer, 2017

Tabel 4 menunjukkan bahwa pada setiap minggunya, pengetahuan responden mengalami peningkatan. Hal ini dapat dilihat dari hasil rerata pengetahuan responden yang terus meningkat. Selain itu, juga terjadi perbedaan pengetahuan yang signifikan dari sebelum diberikan intervensi hingga setelah diberikan intervensi diakhir minggu. Hal ini terlihat dari hasil nilai signifikansi (p) pada Pretest dan Minggu 1, Minggu 1 dan Minggu 2, Minggu 2 dan postest, lebih kecil dari taraf signifikansi $5 \% \quad(p<0,05)$. Hal ini berarti intervensi edukasi menggunakan metode ceramah dengan media leaflet memberikan pengaruah atau perubahan positif terhadap pengetahuan penderita kusta dalam pencegahan penyakit kusta.

Tabel 5 menunjukkan bahwa pada setiap minggunya, sikap responden terhadap penyakit kusta dan pencegahannya mengalami peningkatan. Hal ini dapat dilihat dari hasil rerata sikap responden yang terus meningkat. Selain itu, juga terjadi perbedaan sikap yang signifikan dari sebelum diberikan intervensi (pretest) hingga setelah diberikan intervensi diakhir minggu (postest). Hal ini terlihat dari hasil nilai signifikansi (p) pada Pretest dan Minggu 1, Minggu 1 dan Minggu 2, Minggu 2 dan postest, lebih kecil dari taraf signifikansi $5 \%(\mathrm{p}<0,05)$. Hal ini berarti bahwa intervensi edukasi menggunakan metode ceramah dengan media leaflet memberikan pengaruah atau perubahan positif terhadap sikap penderita kusta dalam pencegahan penyakit kusta.

Sama halnya dengan pengetahuan dan sikap responden, Tabel 6 juga menunjukkan bahwa pada setiap minggunya, tindakan responden terhadap penyakit kusta dan pencegahannya mengalami peningkatan. Hal ini dapat dilihat dari hasil rerata tindakan 
responden yang terus meningkat. Selain itu, juga terjadi perbedaan tindakan yang signifikan dari sebelum diberikan intervensi (pretest) hingga setelah diberikan intervensi diakhir minggu (postest). Hal ini terlihat dari hasil nilai signifikansi (p) pada Pretest dan Minggu 1, Minggu 1 dan Minggu 2, Minggu 2 dan postest, lebih kecil dari taraf signifikansi $5 \%(\mathrm{p}<0,05)$. Hal ini berarti bahwa intervensi edukasi menggunakan metode ceramah dengan media leaflet memberikan pengaruah atau perubahan positif terhadap tindakan penderita kusta dalam pencegahan penyakit kusta.

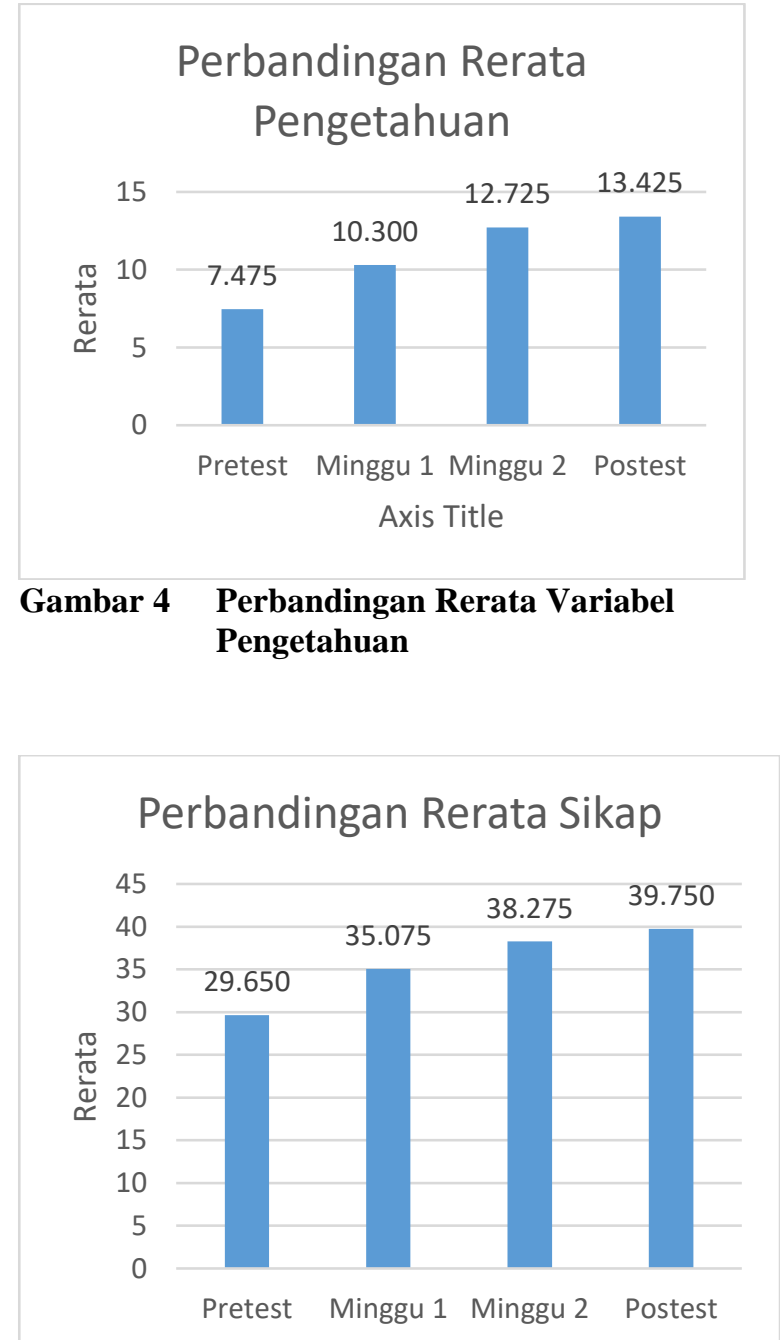

Gambar 5 Perbandingan Rerata Variabel Pengetahuan

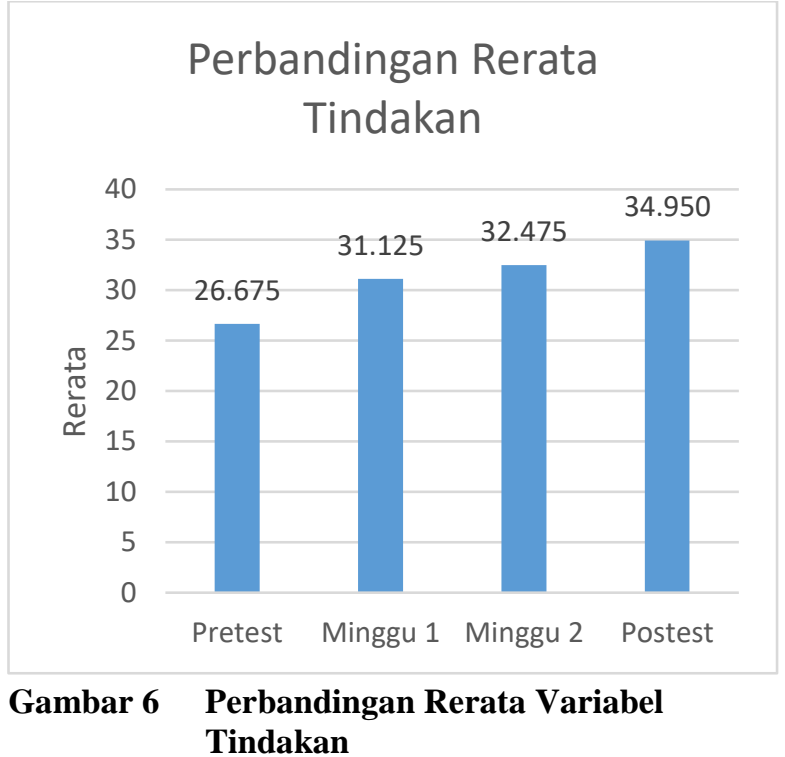

\section{PEMBAHASAN}

Kusta adalah penyakit infeksi kronis yang disebabkan oleh kuman mycobacterium leprae yang menyerang saraf tepi (primer), kulit dan jaringan tubuh lainnya, kecuali susunan saraf pusat. Penyakit kusta merupakan salah satu penyakit menular yang masih ditakuti oleh sebagian masyarakat ataupun keluarga penderita kusta. Hal ini disebabkan masih kurangnya pengetahuan / pengertian, kepercayaan yang keliru terhadap kusta dan cacat yang ditimbulkannya. Oleh sebab itu, penelitian ini dilakukan dengan tujuan memberikan edukasi menggunakan metode ceramah dengan media leaflet dalam pencegahan penyakit kusta sehingga dapat memberikan perubahan atau pengaruh terhadap pemahaman atau pengetahuan, sikap dan tindakan penderita kusta dalam mengatasi penyakit kusta dan pencegahannya.

Hasil penelitian menunjukkan bahwa terdapat pengaruh intervensi edukasi menggunakan metode ceramah dengan media leaflet terhadap peningkatan pengetahuan, 
sikap dan tindakan penderita kusta dalam pencegahan penyakit kusta. Hal ini dibuktikan dari hasil analsiis ke-3 variabel tersebut menunjukkan bahwa dengan nilai signifikansi (p) sebesar 0,000 lebih kecil taraf signifikansi $5 \% \quad(0,000<0,05)$. Selain itu rerata pengetahuan, sikap dan tindakan responden yang mengalami peningkatan setiap minggunya menunjukkan bahwa intervensi edukasi menggunakan metode ceramah dengan media leaflet memberikan dampak perubahan yang positif terhadap pengetahuan, sikap dan tindakan responden.

Hasil penelitian ini sejalan dengan penelitian yang dilakukan oleh Ishak, dkk tentang implementasi penyuluhan kesehatan terhadap perubahan dan sikap tentang penyakit kusta pada masyarakat Desa Suka Pindah Kecamatan Rambutan Kabupaten Banyuasi. Hasilnya menunjukkan bahwa terdapat pengaruh pemberian pendidikan kesehatan terhadap pengetahuan dan sikap tentang penyakit kusta(2).

Pengetahuan merupakan domain yang sangat penting untuk terbentuknya tindakan seseorang ${ }^{(5)}$. Pengetahuan yang dimaksud yaitu pengetahuan responden tentang tentang apa yang dipahami penderita kusta tentang penyakit kusta dan bagaimana pencegahannya. Perilaku yang didasarkan oleh pengetahuan akan lebih langgeng daripada perilaku yang tidak didasari oleh pengetahuan. Oleh sebab itu pengetahuan akan penyakit kusta dan pencegahannya merupakan salah satu penting yang harus penderita kusta ketahui khususnya, dan masyarakat pada umumnya. Selain pengetahuan, sikap atau respon penderita kusta dalam menghadapi penyakit kusta yang diderita dan pencegahan penyakit kusta juga penting.

Sikap (attitude) merupakan reaksi atau respons seseorang yang masih tertutup terhadap suatu stimulus atau objek. Newcomb salah seorang ahli psikologi sosial menyatakan bahwa sikap itu merupakan kesiapan atau kesediaan untuk bertindak, dan bukan merupakan pelaksanaan motif tertentu. Sikap terdiri dari tiga komponen utama yaitu, Kepercayaan/Keyakinan, ide dan konsep terhadap suatu objek, Kehidupan emosional atau evaluasi terhadap suatu objek dan Kecenderungan untuk bertindak (trend to behave) dimana ke-3 komponen inilah yang secara bersama-sama akan membentuk sikap yang utuh. Sikap belum merupakan suatu tindakan atau aktivitas, akan tetapi merupakan 'pre-disposisi' tindakan atau perilaku ${ }^{(6)}$.

Tindakan merupaka wujud nyata dari. Untuk mewujudkan sikap menjadi suatu perbuatan nyata diperlukan faktor pendukung atau suatu kondisi yang memungkinkan, antara lain ada fasilitas ${ }^{(7)}$. Pada penderita kusta, salah satu fasilitas yang dpaat digunakan dalam rangkan pencegahan penyakit kusta yaitu melalui fasilitas kesehatan yang ada dilingkungannya. Salah satu fasilitas kesehatan yang dapat digunakan yaitu memlaui edukasi kesehatan terhadap penderita kusta oleh petugas kesehatan setempat.

Pendidikan kesehatan adalah suatu bentuk intervensi atau upaya yang ditujukan kepada perilaku agar perilaku tersebut 
kondusif untuk kesehatan ${ }^{(8)}$. Lawrence Green menyatakan bahwa pendidikan kesehatan adalah proses perubahan perilaku yang dinamis, di mana perubahan tersebut bukan proses pemindahan materi dari seseorang ke orang lain dan bukan pula seperangkat prosedur. Tujuan utama pendidikan kesehatan yaitu untuk memberikan edukasi kepada masyarakat umumnya untuk memiliki tanggung jawab yang lebih besar terhadap kesehatannya, keselamatan lingkungan dan masyarakatnya.

Pada penderita kusta, salah satu metode yang dapat digunakan dalam memberikan edukasi kesehatan tentang penyakit kusta dan pencegahannya dengan menggunakan metode cermah dengan media leaflet. Penggunaan media dalam promosi kesehatan sangatlah penting. Hal ini dikarenakan media dapat digunakan sebagai alat peraga dalam promosi kesehatan yang dapat dilihat, didengar, dirasa, atau dicium untuk memperlancar komunikasi dan mempermudah perluasan informasi. Leaflet merupakan media publikasi singkat yang pada umumnya berbentuk selebaran yang berisikan keterangan atau informasi yang akan dipublikasikan kepada khalayak. Intervensi pendidikan kesehatan menggunakan ceramah dengan leaflet yang dimaksudkan dalam penelitian ini adalah kegiatan pembelajaran yang dilakukan pada penderita kusta menggunakan media untuk menyampaikan pesan - pesan kesehatan terkait dengan penyakit kusta dan cara mengatasi kecacatan fisik dan pencegahanya. Tujuan dari penggunaan media ini yaitu agar dalam memberikan edukasi terhadap penderita kusta lebih menarik dan tepat sasaran sehingga akan berpengaruh terhadap peningkatan pengetahuan, sikap dan tindakan penderita kusta dalam rangka pencegahan penyakit kusta.

\section{KESIMPULAN DAN SARAN}

Terdapat pengaruh intervensi edukasi menggunakan metode ceramah dengan media leaflet terhadap peningkatan pengetahuan, sikap dan tindakan penderita kusta dalam pencegahan penyakit kusta. Disarankan agar edukasi menggunakan metode ceramah dengan media leaflet dijadikan prosedur dalam pencegahan penyakit kusta.

\section{DAFTAR PUSTAKA}

1. Kemenkes RI, 2014. Pedoman Nasional Program Pengendalian Penyakit Kusta. Dirjen PP dan PL. Jakarta

2. Jurnal Ilmiah, 2013. Rekam Medis dan Informatika Kesehatan Volume 3 No.2

3. Jurnal Ners, 2016. Volume II No.01

4. Dinas Kesehatan Provinsi Sulawesi Tengah. 2016. Data Penderita Kusta Provinsi Sulawesi Tengah tahun 2015.Palu

5. Dinas Kesehatan Kabupaten Tolitoli. 2016. Data Penderita Kusta Kabupaten Tolitoli tahun 2015 dan 2016. Tolitoli

6. Notoatmodjo, 2014. Ilmu Perilaku Kesehatan. Rineka Cipta, Jakarta.

7. Wawan dan Dewi. 2010. Teori dan Pengukuran Pengetahuan Sikap dan Perilaku Manusia. Nuhamedika. Yogyakarta

8. Notoatmodjo, 2007. Pendidikan, promosi dan Prilaku Kesehatan FKM, Depok

9. Notoatmodjo, 2012. Metodologi Penelitian Kesehatan. Rineka Cipta. Jakarta. 